\title{
Computational Modeling and Theoretical Calculations on the Interactions between Spermidine and Functional Monomer (Methacrylic Acid) in a Molecularly Imprinted Polymer
}

\author{
Yujie Huang ${ }^{1,2}$ and Qiujin $\mathrm{Zhu}^{1,3}$ \\ ${ }^{1}$ School of Liquor \& Food Engineering, Guizhou University, Guiyang 550025, China \\ ${ }^{2}$ College of Food Safety, Guizhou Medical University, Guiyang 550025, China \\ ${ }^{3}$ Key Laboratory of Agricultural and Animal Products Store \& Processing of Guizhou Province, Guiyang 550025, China \\ Correspondence should be addressed to Qiujin Zhu; ls.qjzhu@gzu.edu.cn
}

Received 28 September 2015; Accepted 19 November 2015

Academic Editor: Zhonghua Ma

Copyright ( 2015 Y. Huang and Q. Zhu. This is an open access article distributed under the Creative Commons Attribution License, which permits unrestricted use, distribution, and reproduction in any medium, provided the original work is properly cited.

\begin{abstract}
This paper theoretically investigates interactions between a template and functional monomer required for synthesizing an efficient molecularly imprinted polymer (MIP). We employed density functional theory (DFT) to compute geometry, single-point energy, and binding energy $(\Delta E)$ of an MIP system, where spermidine (SPD) and methacrylic acid (MAA) were selected as template and functional monomer, respectively. The geometry was calculated by using B3LYP method with 6-31+(d) basis set. Furthermore, 6$311++(d, p)$ basis set was used to compute the single-point energy of the above geometry. The optimized geometries at different template to functional monomer molar ratios, mode of bonding between template and functional monomer, changes in charge on natural bond orbital (NBO), and binding energy were analyzed. The simulation results show that SPD and MAA form a stable complex via hydrogen bonding. At 1:5 SPD to MAA ratio, the binding energy is minimum, while the amount of transferred charge between the molecules is maximum; SPD and MAA form a stable complex at 1:5 molar ratio through six hydrogen bonds. Optimizing structure of template-functional monomer complex, through computational modeling prior synthesis, significantly contributes towards choosing a suitable pair of template-functional monomer that yields an efficient MIP with high specificity and selectivity.
\end{abstract}

\section{Introduction}

Spermidine (SPD), a polyamine, exists in a variety of organisms and foods $[1,2]$. It regulates different biological processes, such as syntheses of DNA, RNA, and protein [3], and it also plays an important role in biological growth and development of the digestive tract [4]. However, SPD reacts with nitrites in food and generates carcinogenic nitrosamines [5]. Presently, the detection methods of biogenic amines mainly include high performance liquid chromatography (HPLC) [6], ion chromatography (IC) [7], capillary electrophoresis [8], thin layer chromatography [9], gas chromatography [10], biosensor [11], and NMR [12, 13]. These methods involve complex pretreatment and require certain experimental conditions. Molecular imprinting technique (MIT) can produce materials with high selectivity, stability, and specific adsorption capacity $[14,15]$. Therefore, applying MIT to synthesize molecularly imprinted polymers (MIPs) with specific adsorption capacity toward biogenic amines can simplify the pretreatment in the detection of biogenic amines, thereby improving the application range and accuracy of detection.

Typically, synthesis of an MIP requires a template molecule, suitable functional monomer, cross-linking agent, initiator, and suitable initiating condition. Selecting a suitable functional monomer, compatible with template molecule, is crucial because the interaction between functional monomer and template molecule greatly affects specific and selective adsorption of MIPs [16, 17]. Therefore, a computational study prior to MIP synthesis would always be helpful for choosing a suitable pair of template and functional monomer. With the rapid development of computational chemistry, 
TABLE 1: The binding energy for the interaction between template molecule and the functional monomer in the ratio of $1: 1$.

\begin{tabular}{lcc}
\hline Items & $\begin{array}{c}\text { The binding energy } \\
\text { before correction } \\
(\mathrm{KJ} / \mathrm{mol})\end{array}$ & $\begin{array}{c}\text { The binding energy after } \\
\text { correction }(\mathrm{KJ} / \mathrm{mol})\end{array}$ \\
\hline SPD 2-VP & -10.811572705 & -9.5300399 \\
SPD ACN & -7.599798555 & -6.9197678 \\
SPD ALA & -13.132409685 & -11.62912715 \\
SPD MAAM & -31.00521213 & -29.17279692 \\
SPD N-VP & -15.649213985 & -14.51775476 \\
SPD MAA & -52.678163275 & -48.65721002 \\
SPD AM & -16.6551218 & -15.57864055 \\
SPD AA & -50.01026145 & -46.61556871 \\
\hline
\end{tabular}

quantum chemical computation has become an effective technique to understand interactions between a template and a functional monomer prior to synthesizing an MIP, thus ensuring suitable match between template-functional monomer pair to yield maximum specificity and selectivity $[18,19]$. In this regard, density functional theory (DFT) calculation can provide in-depth information with higher accuracy and reliability [20-22]; hence, DFT has been applied on this research.

The commonly used functional monomers include acrylic acid (AA), methacrylic acid (MAA), acrylamide (AM), methacrylamide, and 4-vinyl pyridine [23]. Table 1 shows that MAA and SPD have the lowest binding energy and, thus, produce the most stable complex. Hence, we selected MAA and SPD as the functional monomer and template molecule, respectively, for the simulation to discuss configuration, number of bonds, and binding sites of the complex at different SPD to MAA ratios; the density functional theory (DFT) was employed for modeling. The variation in natural bond orbital (NBO) charge and change in mutual binding energy were also studied.

\section{Calculation Method}

Initially, we drew the 3D structures using GuassianView software. Next, we ran DFT calculations on these input files using Gaussian 09 software. All theoretical computations presented in this study were performed using Gaussian 09 program package installed on the cloud computing platform of Guizhou University. The density functional theory (DFT), a computational quantum mechanical modeling method, was employed to calculate binding energy between a template and a functional monomer and optimize structure. Here, B3LYP method [24-26] was employed; we selected 6-31+(d) as the basis set. The optimized keyword OPT + FRE not only optimized structure but also prevented imaginary frequency. The results obtained from B3LYP computational method were approximately close to crystallographic data (Table 2).

Natural bond orbital (NBO) charge analysis was performed to study position, bond length, and number of hydrogen bonds between SPD and MAA at different SPD to MAA ratios. The basis set $6-311++(\mathrm{d}, \mathrm{p})$ was used to calculate the single-point energy of the optimal structure and explore the interaction between SPD and MAA at different SPD to MAA ratios. Meanwhile, in hydrogen bond-based interaction system, the basis set superposition error (BSSE) cannot be ignored [27]. Therefore, we applied counterpoise procedure (CP) set by Boys and Bernardi [28] for eliminating error in calculation.

\section{Results and Analyses}

3.1. SPD and MAA Optimal Configuration. We used the keyword OPT + FRE for optimal calculation of interactions between template molecule SPD and functional monomer MAA, NBO charge calculation in the optimal structure, and analysis of binding sites. SPD molecule contains two amino $\left(-\mathrm{NH}_{2}\right)$ groups: one at either ends and one imino $(-\mathrm{NH})$ group in the middle (as shown in Figure 1). The $\mathrm{N}$ atoms in amino and imino groups can act as proton acceptor, while the $\mathrm{H}$ atom can act as a proton donor. On the other hand, the $\mathrm{O}$-atom of the carboxyl $(-\mathrm{COOH})$ in MAA can serve as proton acceptor, while the $\mathrm{H}$ atom can serve as proton donor. Figure 1 shows the optimal configurations of both SPD and MAA. Our calculation reveals that the electron acceptors on SPD are $\mathrm{N}_{1}, \mathrm{~N}_{13}$, and $\mathrm{N}_{27}$ with NBO charges of $-0.837,-0.671$, and -0.844 , respectively, while $\mathrm{H}_{2}, \mathrm{H}_{3}, \mathrm{H}_{14}, \mathrm{H}_{28}$, and $\mathrm{H}_{29}$ are the main electron donors with NBO charges of $0.344,0.343$, $0.335,0.343$, and 0.350 , respectively. The atom $\mathrm{O}_{3}$ with $\mathrm{NBO}$ charge -0.601 acts as the main electron acceptor on MAA, while the atom $\mathrm{H}_{5}$ with $\mathrm{NBO}$ charge 0.485 acts as the main electron donor.

3.2. Structure Optimization of SPD-MAA Complex. After optimizing the configurations SPD and MAA individually (with NBO charges at the possible binding sites), we optimized the structure of the complex that might form between SPD and MAA at different imprint ratios. To determine the optimal configuration, we performed calculation for the structures of the complex at different SPD to MAA ratios such as $1: 1,1: 2,1: 3,1: 4$, and $1: 5$. The different spatial configurations between template and functional monomer, number of bonds, and orbitals of functional monomer were analyzed to explore the interaction between SPD and MAA. We found that the binding energy cannot be calculated at the ratios greater than 1:5. We assume that the steric hindrance probably increases the repulsive force and distance, thereby reducing the binding energy between SPD and MAA.

3.2.1. Geometric Configuration. We found a total of five stable configurations of template molecule SPD with MAA, surrounding the former, as shown in Figure 2. Table 3 lists the number of hydrogen bonds, binding sites, and bond length. According to the results, with increasing imprint ratio, the number of hydrogen bonds between SPD and MAA increased and reached six at 1:3 imprint ratio; thereafter it remained the same until 1:5 imprint ratio. The steric hindrance probably caused the increment in the number of hydrogen bonds between template molecule and functional monomer at the binding sites. However, with the increase in imprint ratio, the energy of the entire system decreased, 
TABLE 2: Structural parameters of atrazine calculated using the B3LYP/6-31+(d, p) level and available experimental data.

\begin{tabular}{lccccc}
\hline \multirow{2}{*}{ Parameters } & \multicolumn{2}{c}{ Bond length $(\AA)$} & Parameters & \multicolumn{2}{c}{ Bond angle $\left(^{\circ}\right)$} \\
& Calculating data & Experimental data [29] & & Calculating data & 116.1 \\
Experimental data [29]
\end{tabular}

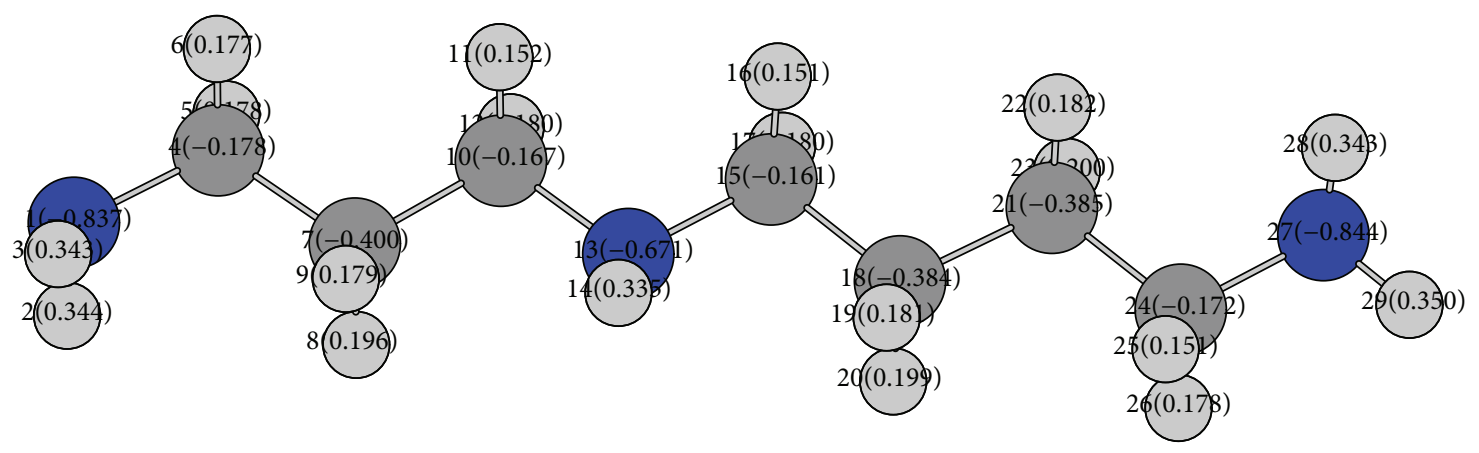

$\mathrm{OH}$

O C

O N

(a) SPD

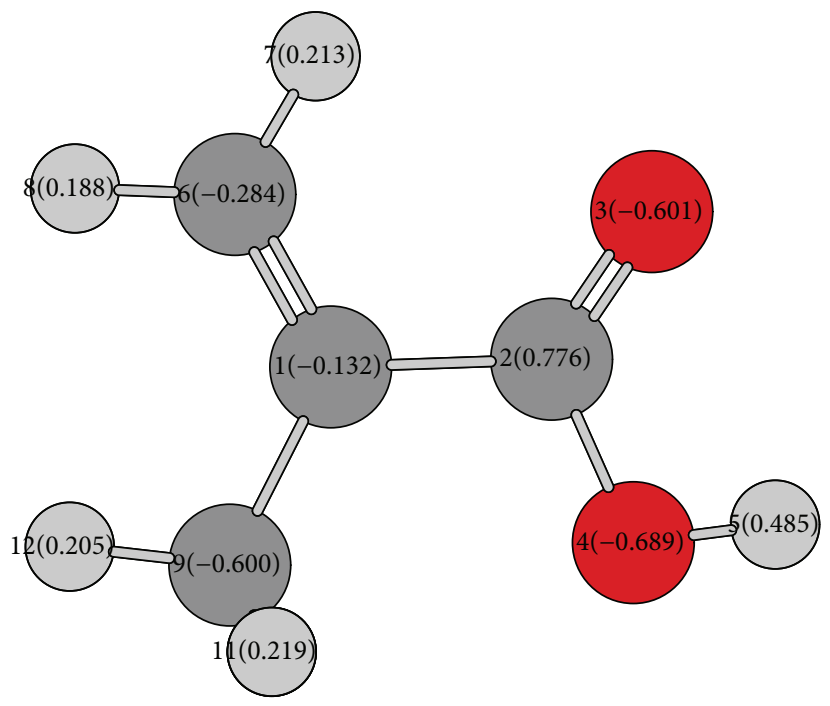

$\mathrm{OH}$

$\mathrm{O} \mathrm{C}$

O $\mathrm{O}$

(b) MAA

FIGURE 1: The optimal configuration of the template molecule and the functional monomer accompanied with NBO charges of each individual atom. 


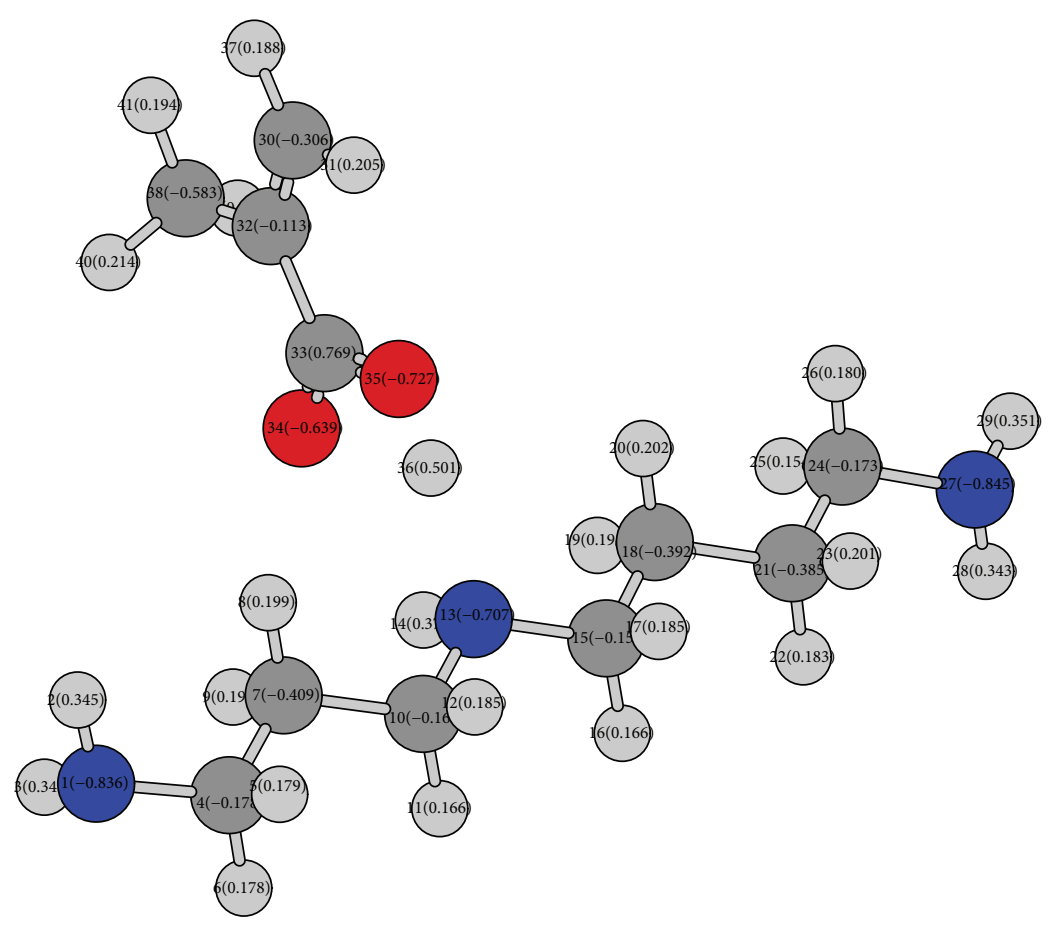

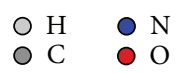

(a)
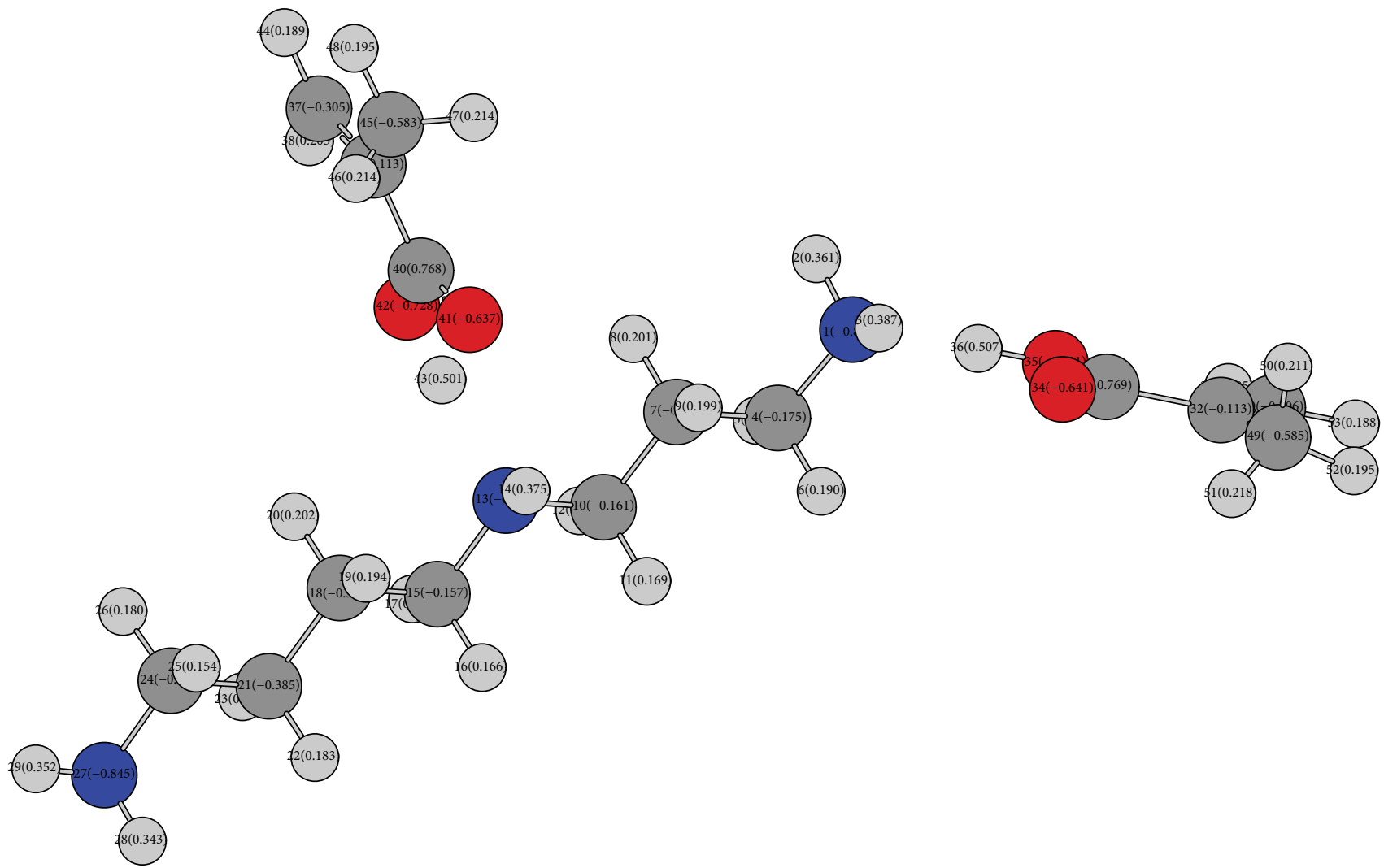

$\begin{array}{lll}\circ \mathrm{H} & \circ \mathrm{N} \\ \mathrm{O} & \mathrm{C} & \mathrm{O}\end{array}$

(b)

Figure 2: Continued. 


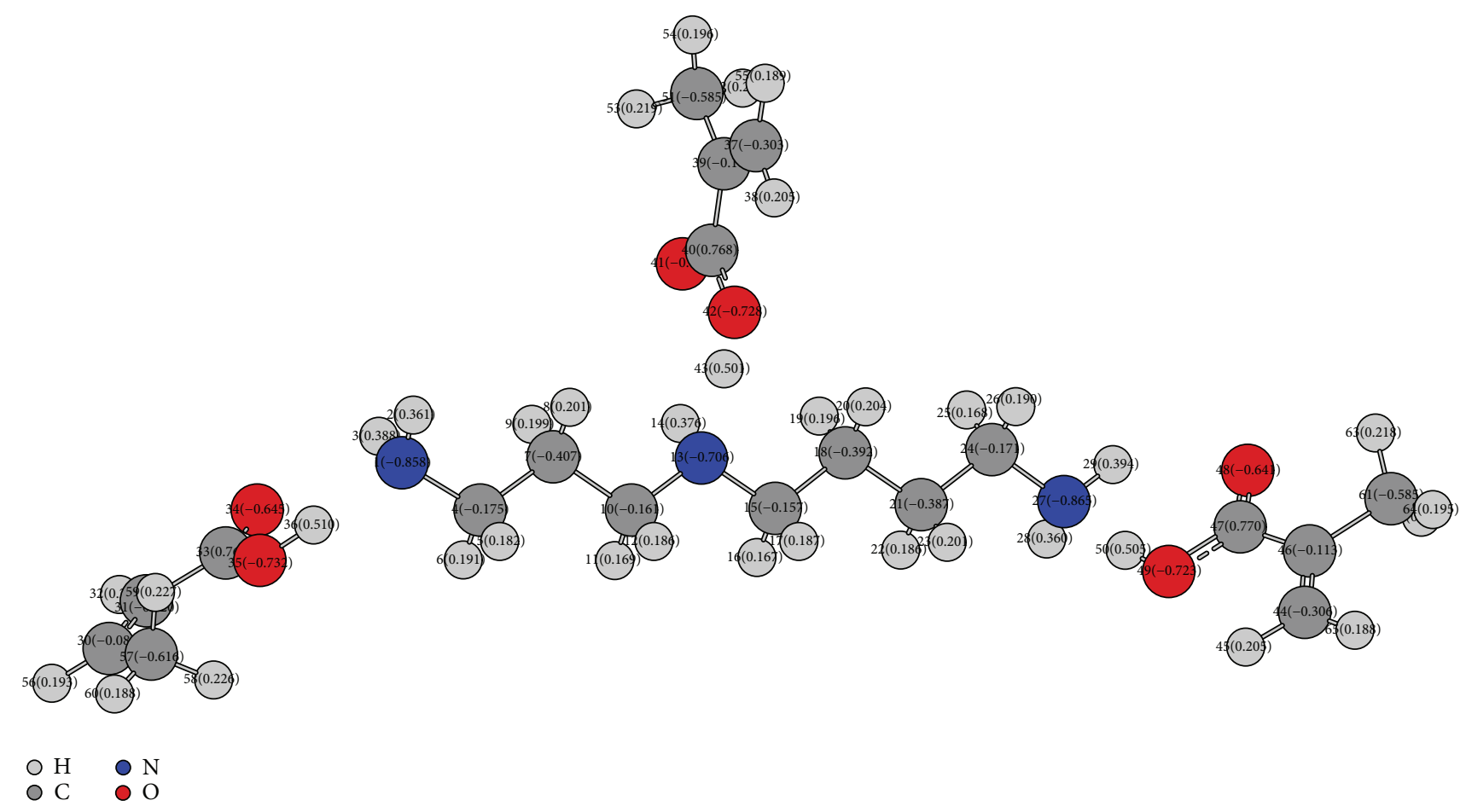

(c)

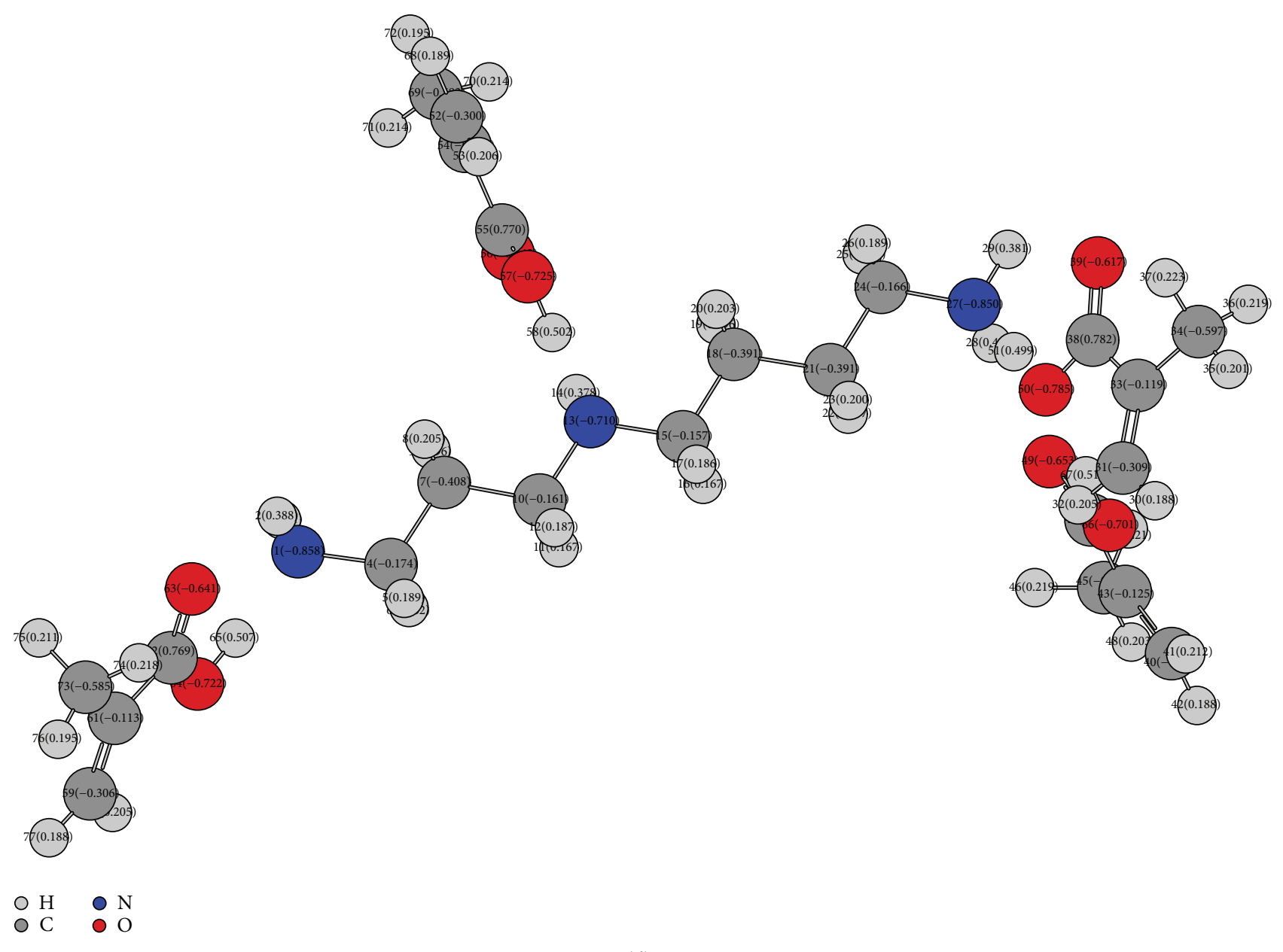

(d)

Figure 2: Continued. 


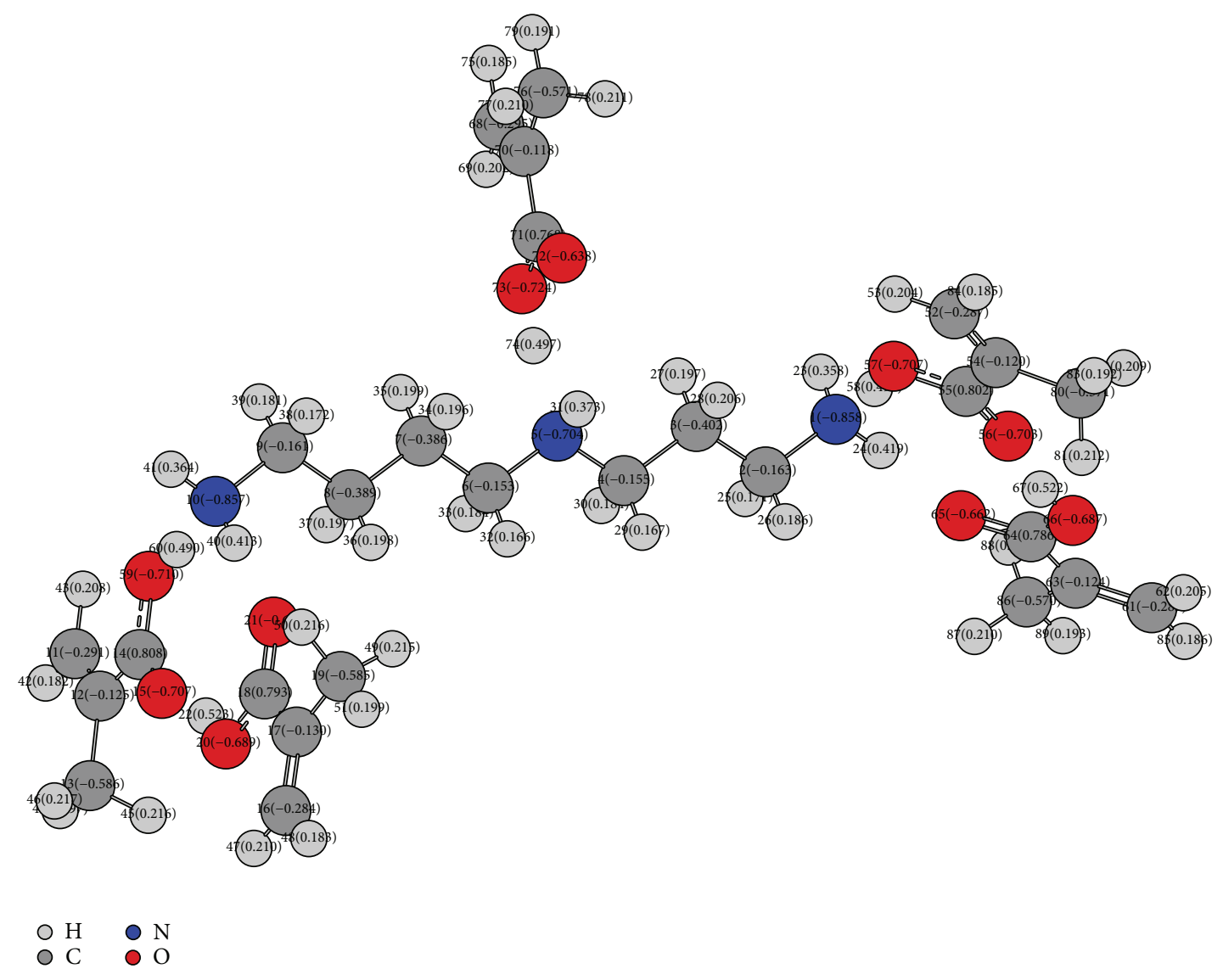

(e)

FiguRE 2: Conformations of the template molecule and the functional monomer at different imprint ratios. (a)-(e) are different geometric configurations at different imprinting proportions $(1: 1 ; 1: 2 ; 1: 3 ; 1: 4$; and $1: 5)$, respectively.

and the complex became more stable. The formation of hydrogen bonds increased active binding sites of an MIP, thereby contributing to specific and selective adsorption.

3.2.2. Binding Energy. We calculated the binding energy between SPD and MAA and used B3LYP/6-311++(d, p) to calculate the single-point energy in the optimal structure; $\mathrm{CP}$ was used to eliminate the basis set superposition error. We calculated the binding energy $\Delta E$ between template molecule and functional monomer using the following equation:

$$
\Delta E=E_{\mathrm{SPD}-T}-E_{\mathrm{SPD}}-\Sigma E_{T}
$$

where $E_{\mathrm{SPD}-T}$ is the energy of mixture, $E_{\mathrm{SPD}}$ is the energy of template molecule SPD, and $\Sigma E_{T}$ is the total energy of functional monomer.

As evident from Table 4, while the energy of the complex system formed by SPD and MAA continuously decreases, the absolute value of binding energy $\Delta E$ continuously increases. However, while changing SPD to MAA ratio, especially, when the ratio increases from $1: 1$ to $1: 2$, the binding energy decreases by $44.99164446 \mathrm{KJ} / \mathrm{mol}$. The stability of the complex begins to improve at $1: 2$ imprint ratio and reaches its minimum $-248.211015535 \mathrm{KJ} / \mathrm{mol}$ at $1: 5$ imprint ratio; moreover, SPD-MAA complex attains the optimum stability at 1:5 imprint ratio.

3.2.3. Charge Distribution. To determine the number and strength of hydrogen bonds formed between SPD and MAA, we employed NBO charge transfer [30]. Figures 1 and 2 show the charge values. At the imprint ratio of $1: 1$, the NBO charges before and after the complex formation are as follows: (i) NBO charges before complex formation (Figure 1), 0.335 on $\mathrm{H}_{14}$ in $\mathrm{SPD},-0.671$ on $\mathrm{N}_{13}$ in $\mathrm{SPD}$, and 0.485 on $\mathrm{H}_{5}$ in MAA; (ii) NBO charges after complex formation (Figure 2), 0.375 on $\mathrm{H}_{14}$ in SPD, -0.707 on $\mathrm{N}_{13}$ in SPD, and 0.501 on $\mathrm{H}_{36}$ in MAA. The gain or loss in NBO charges on the individual atom is evident from the result, suggesting charge transfer from proton donor and proton acceptor in both SPD and MAA. This further suggests that the template molecule SPD and the functional monomer MAA molecule interact via hydrogen bond formation.

At imprint ratio of $1: 2$, the changes in NBO charges after the complex formation are discussed below. The NBO charges before complex formation are $-0.837,-0.671,0.335$, and 0.344 on $\mathrm{N}_{1}, \mathrm{~N}_{13}, \mathrm{H}_{14}$, and $\mathrm{H}_{3}$ in $\mathrm{SPD}$, respectively. After interacting with MAA, NBO charges on $\mathrm{N}_{1}, \mathrm{~N}_{13}, \mathrm{H}_{14}$, and $\mathrm{H}_{3}$ in SPD become -0.858 and $-0.706,0.375$, and 0.387 , respectively. 
TABLE 3: The number of hydrogen bonds, location, and the bond length under different proportions.

\begin{tabular}{|c|c|c|c|}
\hline $\begin{array}{l}\text { Imprinting } \\
\text { ratio }\end{array}$ & $\begin{array}{c}\text { Number of } \\
\text { hydrogen } \\
\text { bonds }\end{array}$ & $\begin{array}{c}\text { Hydrogen } \\
\text { bonding } \\
\text { position }\end{array}$ & $\begin{array}{l}\text { Bond length } \\
\text { (A) }\end{array}$ \\
\hline \multirow{2}{*}{$1: 1$} & \multirow[t]{2}{*}{2} & $\mathrm{~N}_{13}-\mathrm{H}_{35}-\mathrm{O}_{36}$ & 1.72185 \\
\hline & & $\mathrm{N}_{13}-\mathrm{H}_{14}-\mathrm{O}_{34}$ & 2.51531 \\
\hline \multirow{4}{*}{$1: 2$} & \multirow{4}{*}{4} & $\mathrm{O}_{42}-\mathrm{H}_{43}-\mathrm{N}_{13}$ & 1.72303 \\
\hline & & $\mathrm{N}_{13}-\mathrm{H}_{14}-\mathrm{O}_{41}$ & 2.54037 \\
\hline & & $\mathrm{N}_{1}-\mathrm{H}_{36}-\mathrm{O}_{35}$ & 1.72790 \\
\hline & & $\mathrm{O}_{34}-\mathrm{H}_{3}-\mathrm{N}_{1}$ & 2.47553 \\
\hline \multirow{6}{*}{$1: 3$} & \multirow{6}{*}{6} & $\mathrm{~N}_{1}-\mathrm{H}_{36}-\mathrm{O}_{35}$ & 1.72984 \\
\hline & & $\mathrm{O}_{34}-\mathrm{H}_{3}-\mathrm{N}_{1}$ & 2.48082 \\
\hline & & $\mathrm{N}_{13}-\mathrm{H}_{43}-\mathrm{O}_{42}$ & 1.72965 \\
\hline & & $\mathrm{O}_{41}-\mathrm{H}_{14}-\mathrm{N}_{13}$ & 2.53673 \\
\hline & & $\mathrm{N}_{27}-\mathrm{H}_{50}-\mathrm{O}_{49}$ & 1.72705 \\
\hline & & $\mathrm{N}_{27}-\mathrm{H}_{29}-\mathrm{O}_{48}$ & 2.45109 \\
\hline \multirow{6}{*}{$1: 4$} & \multirow{6}{*}{6} & $\mathrm{O}_{64}-\mathrm{H}_{65}-\mathrm{N}_{1}$ & 1.72734 \\
\hline & & $\mathrm{N}_{1}-\mathrm{H}_{2}-\mathrm{O}_{63}$ & 2.46720 \\
\hline & & $\mathrm{N}_{13}-\mathrm{H}_{58}-\mathrm{O}_{57}$ & 1.74120 \\
\hline & & $\mathrm{O}_{56}-\mathrm{H}_{14}-\mathrm{N}_{13}$ & 2.43550 \\
\hline & & $\mathrm{N}_{27}-\mathrm{H}_{51}-\mathrm{O}_{50}$ & 1.54479 \\
\hline & & $\mathrm{O}_{49}-\mathrm{H}_{28}-\mathrm{N}_{27}$ & 2.14838 \\
\hline \multirow{6}{*}{$1: 5$} & \multirow{6}{*}{6} & $\mathrm{~N}_{1}-\mathrm{H}_{24}-\mathrm{O}_{65}$ & 1.94986 \\
\hline & & $\mathrm{O}_{57}-\mathrm{H}_{58}-\mathrm{N}_{1}$ & 1.59082 \\
\hline & & $\mathrm{N}_{5}-\mathrm{H}_{74}-\mathrm{O}_{73}$ & 1.72609 \\
\hline & & $\mathrm{O}_{72}-\mathrm{H}_{31}-\mathrm{N}_{5}$ & 2.53888 \\
\hline & & $\mathrm{O}_{21}-\mathrm{H}_{40}-\mathrm{N}_{10}$ & 1.97375 \\
\hline & & $\mathrm{O}_{59}-\mathrm{H}_{60}-\mathrm{N}_{10}$ & 1.57419 \\
\hline
\end{tabular}

TABLE 4: Interaction energies of template-monomer complexes before and after BSSE correction.

\begin{tabular}{lcc}
\hline $\begin{array}{l}\text { Compound } \\
\text { structure }\end{array}$ & $\begin{array}{c}\text { The binding energy } \\
\text { before correction } \\
(\mathrm{KJ} / \mathrm{mol})\end{array}$ & $\begin{array}{c}\text { The binding energy after } \\
\text { correction }(\mathrm{KJ} / \mathrm{mol})\end{array}$ \\
\hline SPD-MAA & -52.678163275 & -48.65721002 \\
SPD-2MAA & -100.60679705 & -93.64885448 \\
SPD-3MAA & -153.80546570 & -143.51663 \\
SPD-4MAA & -213.61453948 & -200.0685348 \\
SPD-5MAA & -265.734075125 & -248.211015535 \\
\hline
\end{tabular}

Therefore, in SPD, $\mathrm{N}_{1}$ and $\mathrm{N}_{13}$ gain some $\mathrm{NBO}$ charges, while $\mathrm{H}_{14}$ and $\mathrm{H}_{3}$ lose NBO charges after interacting with MAA. In comparison with imprinting ratio $1: 1$, one more electron donor and one more electron acceptor sites are added at 1:2 SPD to MAA ratio, resulting in the formation of two more hydrogen bonds between the template and functional monomer.
At the imprint ratio of $1: 3$, the following changes occur with regard to the $\mathrm{NBO}$ charges before and after complex formation. The $\mathrm{NBO}$ charges on $\mathrm{N}_{1}, \mathrm{~N}_{13}$, and $\mathrm{N}_{27}$ in SPD are $-0.837,-0.671$, and -0.844 , respectively. After MAA interaction, the $\mathrm{NBO}$ charges on $\mathrm{N}_{1}, \mathrm{~N}_{13}$, and $\mathrm{N}_{27}$ become $-0.858,-0.706$, and -0.865 , respectively. Therefore, overall charge increase occurs in each of $\mathrm{N}$ atoms mentioned above. After interacting with MAA, increase in charge also occurs in hydrogen atoms $\left(\mathrm{H}_{3}=0.343\right.$ to $0.388, \mathrm{H}_{14}=0.335$ to 0.376 , and $\mathrm{H}_{29}=0.350$ to 0.394 ) of SPD. Compared with imprinting ratio $1: 2$, at imprinting ratio $1: 3$, one more electron donor and one more electron acceptor sites are added to the system, contributing to the formation of two more hydrogen bonds.

At imprint ratio of $1: 4$, the changes in NBO charges on $\mathrm{N}$ and $\mathrm{H}$ atoms in SPD after complex formation are as follows: $\mathrm{N}_{1}=-0.837$ to $-0.858, \mathrm{~N}_{13}=-0.671$ to $-0.710, \mathrm{~N}_{27}=-0.844$ to $-0.850, \mathrm{H}_{2}=0.344$ to $0.388, \mathrm{H}_{14}=0.335$ to 0.378 , and $\mathrm{H}_{28}$ $=0.343$ to 0.405 . Therefore, overall charge increment occurs in both $\mathrm{N}$ and $\mathrm{H}$ atoms in SPD as mentioned above. No excess hydrogen bond forms at imprinting ratio $1: 4$ compared with imprinting ratio $1: 3$. However, the hydroxyl group on SPD molecule and the carbonyl groups of two MAA molecules form a new hydrogen bond.

Finally, at imprinting ratio $1: 5$, we also noted overall NBO charge increase on both $\mathrm{N}$ and $\mathrm{H}$ atoms in SPD after interacting with MAA. The changes are as follows: $\mathrm{N}_{1}=$ -0.837 to $-0.858, \mathrm{~N}_{5}=-0.761$ to $-0.704, \mathrm{~N}_{10}=-0.844$ to $-0.857, \mathrm{H}_{24}=0.344$ to $0.419, \mathrm{H}_{31}=0.335$ to 0.373 , and $\mathrm{H}_{40}=0.350$ to 0.413 . No extra hydrogen bond forms at imprinting ratio $1: 5$ compared with imprinting ratio $1: 3$. However, the NBO charge transfer occurs between two MAA molecules located at both ends of SPD molecule, leading to the formation of hydrogen bonds between MAA molecules.

\section{Conclusions}

To understand the interactions between a template molecule (SPD) and functional monomer(s) (MAA), we performed computational modeling using DFT and calculated optimal configuration of the complex formed (SPD-MAA), number of binding sites, bonding situation, and binding energy at different imprint ratios (template to functional ratios). The results obtained from theoretical calculations together suggest that the most stable complex with the lowest energy formed between SPD and MAA at the imprint ratio of $1: 5$; the complex formed through six hydrogen bonds $\left(\mathrm{N}_{1}-\mathrm{H}_{24}-\mathrm{O}_{65} ; \mathrm{O}_{57}-\mathrm{H}_{58}-\mathrm{N}_{1} ; \mathrm{N}_{5}-\mathrm{H}_{74}-\mathrm{O}_{73} ; \mathrm{O}_{72}-\right.$ $\left.\mathrm{H}_{31}-\mathrm{N}_{5} ; \mathrm{O}_{21}-\mathrm{H}_{40}-\mathrm{N}_{10} ; \mathrm{O}_{59}-\mathrm{H}_{60}-\mathrm{N}_{10}\right)$. Optimizing experimental conditions using computational modeling prior to MIP synthesis reduces unnecessary consumption of raw materials and saves time. Therefore, computational methods would serve as a guiding tool for choosing a compatible pair of template and functional monomer that yields a highly specific and selective MIP.

\section{Conflict of Interests}

The authors declare no conflict of interests. 


\section{Acknowledgments}

This work is supported by the Natural Science Foundation of China (31160324), the Outstanding Scientific and Technological Talents Training Plan of Guizhou Province (QKHRZ 201107), and Key Project in Agriculture of Guizhou Province in 2011 (2011-3099).

\section{References}

[1] A. R. Shalaby, "Significance of biogenic amines to food safety and human health," Food Research International, vol. 29, no. 7, pp. 675-690, 1996.

[2] A. Y. Smit, W. J. Du Toit, and M. Du Toit, "Biogenic amines in wine: understanding the headache," South African Journal of Enology \& Viticulture, vol. 29, no. 2, pp. 109-127, 2008.

[3] K. Igarashi and K. Kashiwagi, "Modulation of cellular function by polyamines," The International Journal of Biochemistry and Cell Biology, vol. 42, no. 1, pp. 39-51, 2010.

[4] M. Sabater-Molina, E. Larqué, F. Torrella et al., "Effects of dietary polyamines at physiologic doses in early-weaned piglets," Nutrition, vol. 25, no. 9, pp. 940-946, 2009.

[5] S. Bardocz, "The role of dietary polyamines," European Journal of Clinical Nutrition, vol. 47, no. 10, pp. 683-690, 1993.

[6] A. Önal, "A review: current analytical methods for the determination of biogenic amines in foods," Food Chemistry, vol. 103, no. 4, pp. 1475-1486, 2007.

[7] C. Palermo, M. Muscarella, D. Nardiello, M. Iammarino, and D. Centonze, "A multiresidual method based on ion-exchange chromatography with conductivity detection for the determination of biogenic amines in food and beverages," Analytical and Bioanalytical Chemistry, vol. 405, no. 2-3, pp. 1015-1023, 2013.

[8] A. Bacaloni, S. Insogna, A. Sancini, M. Ciarrocca, and F. Sinibaldi, "Sensitive profiling of biogenic amines in human urine by capillary electrophoresis with field amplified sample injection," Biomedical Chromatography, vol. 27, no. 8, pp. 987993, 2013.

[9] A. Romano, H. Klebanowski, S. La Guerche et al., "Determination of biogenic amines in wine by thin-layer chromatography/densitometry," Food Chemistry, vol. 135, no. 3, pp. 13921396, 2012.

[10] B.-S. Hwang, J.-T. Wang, and Y.-M. Choong, "A rapid gas chromatographic method for the determination of histamine in fish and fish products," Food Chemistry, vol. 82, no. 2, pp. 329334, 2003.

[11] J. Lange and C. Wittmann, "Enzyme sensor array for the determination of biogenic amines in food samples," Analytical and bioanalytical chemistry, vol. 372, no. 2, pp. 276-283, 2002.

[12] F. Shi, A. M. Coffey, K. W. Waddell, E. Y. Chekmenev, and B. M. Goodson, "Heterogeneous solution NMR signal amplification by reversible exchange," Angewandte Chemie International Edition, vol. 126, no. 29, pp. 7625-7628, 2014.

[13] F. Shi, A. M. Coffey, K. W. Waddell, E. Y. Chekmenev, and B. M. Goodson, "Nanoscale catalysts for NMR signal enhancement by reversible exchange," The Journal of Physical Chemistry C, vol. 119, no. 13, pp. 7525-7533, 2015.

[14] L. Chen, S. Xu, and J. Li, "Recent advances in molecular imprinting technology: current status, challenges and highlighted applications," Chemical Society Reviews, vol. 40, no. 5, pp. 2922-2942, 2011.
[15] G. Vasapollo, R. D. Sole, L. Mergola et al., "Molecularly imprinted polymers: present and future prospective," International Journal of Molecular Sciences, vol. 12, no. 9, pp. 5908-5945, 2011.

[16] E. Yilmaz, K. Mosbach, and K. Haupt, "Influence of functional and cross-linking monomers and the amount of template on the performance of molecularly imprinted polymers in binding assays," Analytical Communications, vol. 36, no. 5, pp. 167-170, 1999.

[17] I. Chianella, K. Karim, E. V. Piletska, C. Preston, and S. A. Piletsky, "Computational design and synthesis of molecularly imprinted polymers with high binding capacity for pharmaceutical applications-model case: adsorbent for abacavir," Analytica Chimica Acta, vol. 559, no. 1, pp. 73-78, 2006.

[18] D. Pavel, J. Lagowski, and C. J. Lepage, "Computationally designed monomers for molecular imprinting of chemical warfare agents-part V,' Polymer, vol. 47, no. 25, pp. 8389-8399, 2006.

[19] A. Wach, J. Chen, Z. Falls et al., "Determination of the structures of molecularly imprinted polymers and xerogels using an automated stochastic approach," Analytical Chemistry, vol. 85, no. 18, pp. 8577-8584, 2013.

[20] Y. Diñeiro, M. I. Menéndez, M. C. Blanco-López, M. J. Lobo-Castañón, A. J. Miranda-Ordieres, and P. Tuñón-Blanco, "Computational approach to the rational design of molecularly imprinted polymers for voltammetric sensing of homovanillic acid," Analytical Chemistry, vol. 77, no. 20, pp. 6741-6746, 2005.

[21] A. Kowalska, A. Stobiecka, and S. Wysocki, "A computational investigation of the interactions between harmane and the functional monomers commonly used in molecular imprinting," Journal of Molecular Structure: THEOCHEM, vol. 901, no. 1-3, pp. 88-95, 2009.

[22] Y. Liu, F. Wang, T. Tan, and M. Lei, "Study of the properties of molecularly imprinted polymers by computational and conformational analysis," Analytica Chimica Acta, vol. 581, no. 1, pp. 137-146, 2007.

[23] F. Ahmadi, J. Ahmadi, and M. Rahimi-Nasrabadi, "Computational approaches to design a molecular imprinted polymer for high selective extraction of 3,4-methylenedioxymethamphetamine from plasma," Journal of Chromatography A, vol. 1218, no. 43, pp. 7739-7747, 2011.

[24] E. Piletska, S. Piletsky, K. Karim, E. Terpetschnig, and A. Turner, "Biotin-specific synthetic receptors prepared using molecular imprinting," Analytica Chimica Acta, vol. 504, no. 1, pp. 179-183, 2004.

[25] C. Zhang, J. Hu, S. Chen, and F. Ji, "Theoretical study of hydrogen bonding interactions on MDI-based polyurethane," Journal of Molecular Modeling, vol. 16, no. 8, pp. 1391-1399, 2010.

[26] P. J. Stephens, F. J. Devlin, C. F. Chabalowski, and M. J. Frisch, "Ab initio calculation of vibrational absorption and circular dichroism spectra using density functional force fields," The Journal of Physical Chemistry, vol. 98, no. 45, pp. 11623-11627, 1994.

[27] M. Tabandeh, S. Ghassamipour, H. Aqababa, M. Tabatabaei, and M. Hasheminejad, "Computational design and synthesis of molecular imprinted polymers for selective extraction of allopurinol from human plasma," Journal of Chromatography B, vol. 898, pp. 24-31, 2012.

[28] S. F. Boys and F. D. Bernardi, "The calculation of small molecular interactions by the differences of separate total energies. Some procedures with reduced errors," Molecular Physics, vol. 19, no. 4, pp. 553-566, 1970. 
[29] E. Giglio, A. M. Liquori, R. Puliti, and A. Ripamonti, "The crystal structure of spermidine trihydrochloride," Acta Crystallographica, vol. 20, no. 5, pp. 683-688, 1966.

[30] T. Steiner, "The hydrogen bond in the solid state," Angewandte Chemie International Edition, vol. 41, no. 1, pp. 48-76, 2002. 

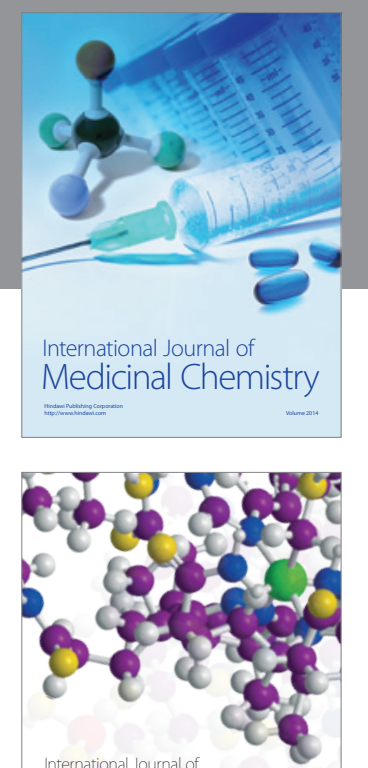

\section{Carbohydrate} Chemistry

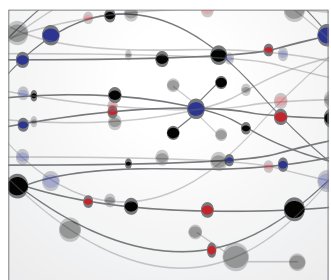

The Scientific World Journal
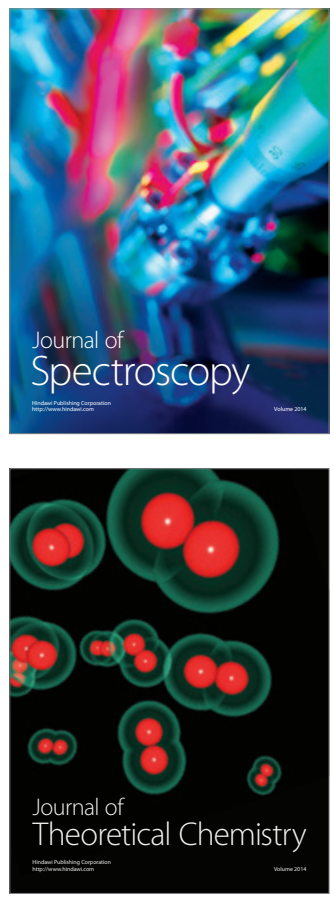
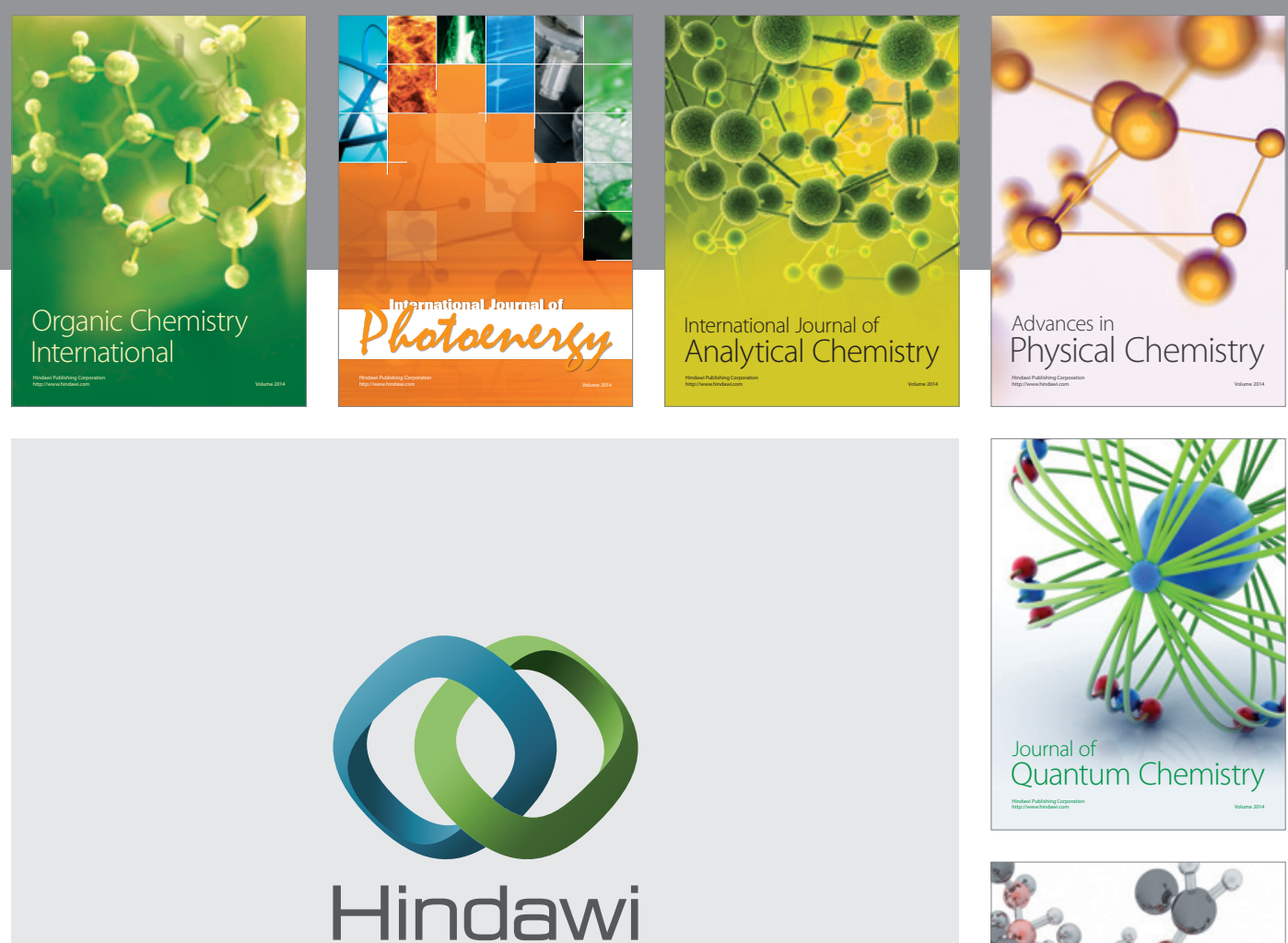

Submit your manuscripts at

http://www.hindawi.com

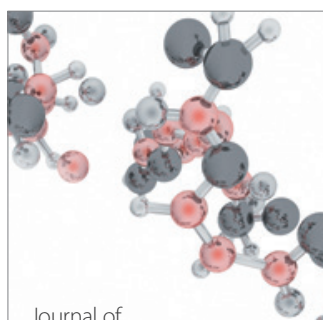

Analytical Methods

in Chemistry

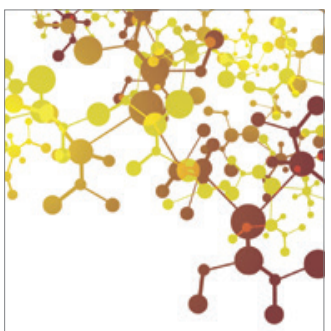

Journal of

Applied Chemistry

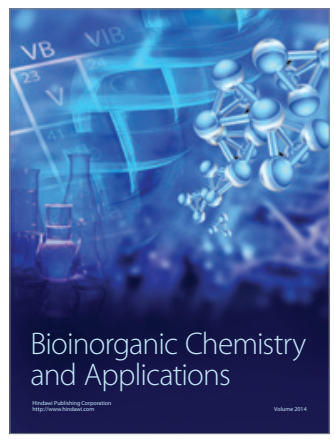

Inorganic Chemistry
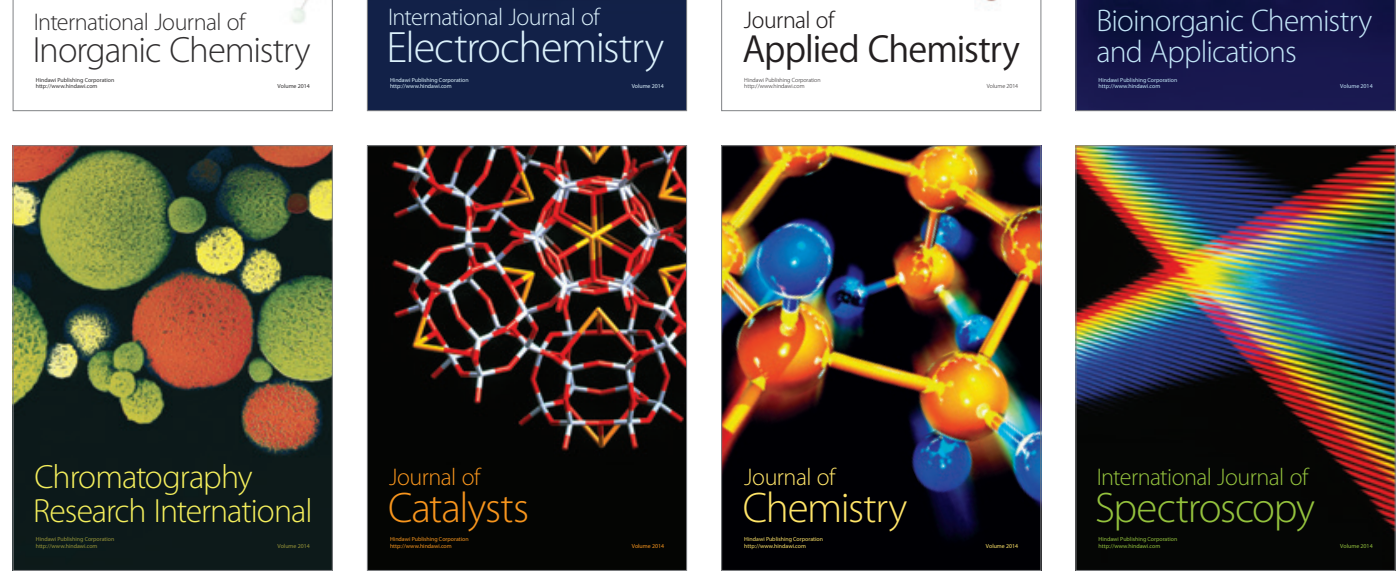